\title{
Gene Functional Studies Using Bacterial Artificial Chromosome (BACs)
}

\author{
Mingli Liu, Shanchun Guo, Monica Battle and Jonathan K. Stiles \\ Microbiology, Biochemistry and Immunology \\ Morehouse School of Medicine, Atlanta
}

USA

\section{Introduction}

\subsection{Background and history of bacterial artificial chromosome (BACs)}

BACs were first developed as a large insert cloning system to facilitate the construction of DNA libraries to analyze genomic structure (Shizuya, Birren et al. 1992). BACs are derived from a fertility plasmid (F-plasmid) found in the Escherichia coli. BACs can clone extremely large DNA molecules, ranging from $150-700 \mathrm{~kb}$, and averaging $350 \mathrm{~kb}$. Another advantage of BACs over other cloning technologies is its stability in cell culture and ease of manipulation. Because some recombinant viruses were too large to be generated by traditional techniques, BAC technology was developed to carry out genetic and functional studies of viruses, especially herpesvirus. (Warden, Tang et al. 2011). From the time when BACs emerged a decade ago, their application have grown intensely and have benefited the research community in many fields, such as sequencing of the human genome, in vitro transgenesis, genomic fingerprinting, and even to vaccine development.

\subsection{BACs generation}

BACs can be considered as plasmid expression vectors, amplified in bacteria and composed of a small amount of bacterial DNA derived from the single copy F-plasmid (Shizuya, Birren et al. 1992). F-plasmid has genes required for prokaryotic replication, partition, and selection. Viral BACs are generated by inserting a BAC vector sequence into a viral genome (Warden, Tang et al. 2011). Direct deletion mutants and random transposon mutagenesis of viral BACs are commonly used to determine the function of viral genes (Warden, Tang et al. 2011). Mammalian DNA, human genome or mouse genome (100-350 kb) can also be cloned as BACs vectors. Currently most regions of the human genome and the genome of other species are available as BACs. These vectors are useful tools in human genome-sequencing projects (Lander, Linton et al. 2001; Venter, Adams et al. 2001) and transgenic mice studies. Using endogenous homologous recombination systems in E. coli (Copeland, Jenkins et al. 2001), BACs can be modified in many ways by recombination. They can be genetically engineered to express reporter genes, or to put a transgene under a specific promoter which will be more amenable in gene expression in the mammalian cells. BACs can be modified to replace any nucleotide sequence of interest (gene replacement), remove any existing DNA 
sequence, or introduce new sequences without removing any of the existing sequences (gene removal or insertion). In addition BACs are also used to place nucleotide substitution through selection/counterselection strategy, and to conduct effective gap repair cloning of any target site of interest (Adamson, Jackson et al. 2011).

\subsection{Advantages and disadvantages of BACs}

Genes expressed from BACs mirror endogenous gene expression far more accurately than other cloning systems. The large size of BACs help to minimize site of integration effects, a phenomenon which has been defined as endogenous sequences (such as gene coding regions and distal regulatory elements) to be disrupted, and to produce potentially undesirable phenotypes (Adamson, Jackson et al. 2011) in gene cloning technology. The larger sized BAC constructs contain enhancers and locus control regions, which leads to more accurate gene expression in vivo (Townes, Lingrel et al. 1985; Jones, Monks et al. 1995). 1995). The human genome BACs consist of the full gene structure, including untranslated regions, exons and introns, alternative promoters and splice sites and microRNA coding sequences. RNAs such as RNA splicing or microRNAs play very important role in gene regulation (Jackson and Standard 2007). Therefore the human genome BACs will ensure full mRNA processing and splicing when genes are transcribed, and produce the full complement of protein isoforms once mRNAs are translated. BACs can be transfected and expressed in mammalian cell lines although transfection efficiency and copy numbers are low (Magin-Lachmann, Kotzamanis et al. 2004; Sparwasser and Eberl 2007).

BACs also have a number of disadvantages. A construct containing a large genomic fragment is likely to contain non-related genes that may lead to indirect, non-specific gene expression and unanticipated changes in the cell phenotype; Secondly, compared to plasmids or other gene expression vectors, the generation and screening of recombinant BAC constructs can be time-consuming and labor-intensive. Also, the oversized BAC DNA constructs are more easily sheared and degraded during manipulation before transfection; and some random recombination events may occur, for example, LoxP sites may lead to random Cre-mediated recombination (Semprini, Troup et al. 2007). Finally, repeating homologous sequences in some BACs constructs may undergo intramolecular rearrangements, which reduce the recombination efficiency and increase the rate of falsepositive clones in some selection/counter-selection approaches (Narayanan 2008).

Overall, BACs have numerous advantages when compared to conventional plasmids. They protect the gene from site of integration effects and produce accurate regulation of transcription and translation. However, the large size results in technical difficulties when handling them as well as the potential non-specific gene expression. Therefore the application of BACs as a gene expression model system should be careful considered based on the pros and cons previously described.

\subsection{Application of BACs: Genomic sequencing, genomic imprinting, transgenic mice, vaccine development, and gene therapy}

There is increasing interest in the application of BAC technology in genomic research. High throughput determination of gains and losses of genetic material using high resolution BAC 
arrays and comparative genomic hybridization ( $\mathrm{CGH}$ ) have been developed into the new tools for translational research in solid tumors and neurodegenerative disorders (Cowell and Nowak 2003; Cowell 2004; Costa, Meijer et al. 2008; Lu 2009). Among a large number of approaches for sequencing, BAC technology is becoming the most robust method for genome sequencing. The BAC-by-BAC technique uses an overlapping tilling path of large genomic fragments (150-200 kb) maintained within BACs. Every individual BAC is shotgun sequenced. Many short reads are assembled to produce the sequence of the BACs, where these large overlapping sequences of the BACs are assembled to produce the who genome sequence (Imelfort, Batley et al. 2009). BACs have also been used in mammalian genome mapping (Schalkwyk, Francis et al. 1995), genomic imprinting (Tunster, Van De Pette et al. 2011), vaccine development and gene therapy (Magin-Lachmann, Kotzamanis et al. 2004; Warden, Tang et al. 2011). Studies of the evolutionary history and functional dynamics of sex chromosomes have recently been possible using BAC libraries (Janes, Valenzuela et al. 2011). In this chapter we will review some applications of BACs in viral and non-viral gene functional studies.

\section{Viral gene functional studies}

\subsection{Many human and animal herpesviruses genomes have been cloned as BACs}

Human herpesviruses are the second leading cause of human viral disease. Therefore the utilization of human herpesvirus BACs to study viral gene function (Warden, Tang et al. 2011) has become more and more common. The herpesviruses are a family of DNA viruses which contain large and complex genomes. Genetic control and management of recombinant viruses have been notoriously difficult. The development of herpesvirus BACs have facilitated generation of recombinant viruses and subsequent studies of the biology and pathogenesis of herpesviruses (Knipe, Batterson et al. 1981; Zhou and Roizman 2005). Table 1 shows the human herpesviruses which have been cloned as BACs, including Herpes simples virus type 1 [(HSV-1 or human herpesvirus (HHV-1)], varicella-zoster virus (VZV or HHV-3), human cytomegalovirus (HCMV or HHV-5), Kaposi's sarcoma-associated herpesvirus (KSHV or HHV-8) (Feederle, Bartlett et al. 2010; Warden, Tang et al. 2011). In general, BAC clones are relatively easy to make for alpha- and beta herpes viruses than gamma herpes viruses. This is due to the fact that DNA can only persistently stay in bacterial cells when it has a prokaryotic replicon. When a BACs flanked by specific Herpesvirus genomic sequences were introduced into infected cells to trigger homologous recombination. The great efficiency was achieved in alpha- and beta herpes viruses because lytic cellular systems are available, but was difficult for gamma herpesviruses (Delecluse, Hilsendegen et al. 1998; Delecluse, Kost et al. 2001; Zhou, Zhang et al. 2002; Kanda, Yajima et al. 2004; Chen, Li et al. 2007). In addition to BAC-based human herpesvirus studies, BACbased other animal herpesviruses are also currently available. These include murine cytomegalovirus 68 (MHV-68), murine gammaherpesvirus (mCMV), rhesus cytomegalovirus (rhCMV), rhesus rhadinovirus (RRV), pseudorabies virus (PrV), herpesvirus saimiri (HVS), Marek's disease virus (MDV), bovine herpesvirus type 1 (BHV1 ), equine herpesvirus type 1 (EHV-1), feline herpesvirus (FHV-1), guinea pig cytomegalovirus (GPCMV), Koi herpesvirus (KHV) and turkery herpesvirus (HVT) (Feederle, Bartlett et al. 2010; Warden, Tang et al. 2011). 


\begin{tabular}{|c|c|c|c|c|}
\hline type & synonym & subfamily & biological function and application & reference \\
\hline HHV-1 & $\begin{array}{l}\text { Herpes } \\
\text { simplex } \\
\text { virus-1 } \\
\text { (HSV-1) }\end{array}$ & a (Alpha) & $\begin{array}{l}\text { Generates a replication-proficient but } \\
\text { packaging-deficient HSV-1 genome } \\
(152-\mathrm{kb} \text { HSV-1) for genetic } \\
\text { manipulation as research tools or } \\
\text { vectors in gene therapy. }\end{array}$ & $\begin{array}{l}\text { (Saeki, } \\
\text { Ichikawa } \\
\text { et al. 1998; } \\
\text { Stavropoulos } \\
\text { and Strathdee } \\
\text { 1998; } \\
\text { Horsburgh, } \\
\text { Hubinette } \\
\text { et al. 1999) }\end{array}$ \\
\hline HHV-2 & $\begin{array}{l}\text { Herpes } \\
\text { simplex } \\
\text { virus-2 } \\
\text { (HSV-2) }\end{array}$ & a & $\begin{array}{l}\text { Generates a recombinant HSV-2 BAC } \\
\text { with the deletion of the HSV-2 } \\
\text { glycoprotein D (gD), elicites an HSV-2 } \\
\text { specific antibody response, serves as the } \\
\text { basis for novel HSV-2 vaccine } \\
\text { production. }\end{array}$ & $\begin{array}{l}\text { (Meseda, } \\
\text { Schmeisser } \\
\text { et al. 2004) }\end{array}$ \\
\hline \multirow{3}{*}{\multicolumn{2}{|c|}{$\begin{array}{l}\text { HHV-3 } \\
\text { Varicella zoster virus } \\
(\mathrm{VZV})\end{array}$}} & \multirow{3}{*}{ a } & $\begin{array}{l}\text { Human embryonic lung cells } \\
\text { transfected with VZV BAC DNA show } \\
\text { cytopathic effect, and viruses can } \\
\text { spread to neighboring cells. }\end{array}$ & $\begin{array}{l}\text { (Nagaike, Mori } \\
\text { et al. 2004) }\end{array}$ \\
\hline & & & $\begin{array}{l}\text { Luciferase VZV BAC generates } \\
\text { recombinant VZV variants, eases } \\
\text { subsequent viral growth kinetic } \\
\text { analysis both in vitro MeWo cells and } \\
\text { SCID-hu mice in vivo. }\end{array}$ & $\begin{array}{l}\text { (Zhang, Rowe } \\
\text { et al. 2007) }\end{array}$ \\
\hline & & & $\begin{array}{l}\text { The mini-F transposition technique } \\
\text { optimizes, repairs or restructures BACs, } \\
\text { facilitates the development of gene } \\
\text { therapy or vaccine vectors. }\end{array}$ & $\begin{array}{l}\text { (Wussow, } \\
\text { Fickenscher } \\
\text { et al. 2009) }\end{array}$ \\
\hline \multirow{2}{*}{\multicolumn{2}{|c|}{$\begin{array}{l}\text { HHV-4 } \\
\text { Epstein-Barr } \\
\text { virus (EBV), lymphoc } \\
\text { ryptovirus (LCV) }\end{array}$}} & \multirow[b]{2}{*}{ Y (Gamma) } & $\begin{array}{l}\text { Genetic analysis of all EBV functions, } \\
\text { generation of attenuated EBV strains for } \\
\text { vaccine design, development of viral } \\
\text { vectors for human gene therapy. }\end{array}$ & $\begin{array}{l}\text { (Delecluse, } \\
\text { Hilsendegen } \\
\text { et al. 1998; } \\
\text { Kanda, Yajima } \\
\text { et al. 2004) }\end{array}$ \\
\hline & & & $\begin{array}{l}\text { Generates a self-recombining BAC } \\
\text { containing } 172-\mathrm{kb} \text { of the EBV genome; } \\
\text { provides proof that EBNA-3B is not } \\
\text { essential for EBV-mediated B-cell } \\
\text { growth transformation in vitro. }\end{array}$ & $\begin{array}{l}\text { (Chen, } \\
\text { Divisconte } \\
\text { et al. 2005) }\end{array}$ \\
\hline
\end{tabular}




\begin{tabular}{|c|c|c|c|c|}
\hline type & synonym & subfamily & biological function and application & reference \\
\hline \multirow{6}{*}{\multicolumn{2}{|c|}{$\begin{array}{l}\text { HHV-5 } \\
\text { Cytomegalovirus } \\
\text { (HCMV) }\end{array}$}} & \multirow{6}{*}{$\beta$ (Beta) } & $\begin{array}{l}\text { A new approach for construction of } \\
\text { HCMV mutants. }\end{array}$ & $\begin{array}{l}\text { (Borst, Hahn } \\
\text { et al. 1999) }\end{array}$ \\
\hline & & & $\begin{array}{l}\text { IE-2 (UL122) is required for successful } \\
\text { HCMV infection and indicates that } \\
\text { virus lacking IE- } 2 \text { arrests early in the } \\
\text { replication cycle. }\end{array}$ & $\begin{array}{l}\text { (Marchini, Liu } \\
\text { et al. 2001) }\end{array}$ \\
\hline & & & $\begin{array}{l}\text { UL45 is dispensable for growth of } \\
\text { HCMV in human fibroblasts and } \\
\text { human endothelial cells }\end{array}$ & $\begin{array}{l}\text { (Hahn, Khan } \\
\text { et al. 2002) }\end{array}$ \\
\hline & & & $\begin{array}{l}\text { A total of } 252 \text { ORFs with the potential } \\
\text { to encode proteins have been identified } \\
\text { in two laboratory strains (AD169 and } \\
\text { Towne) and four clinical isolates } \\
\text { Toledo, FIX, PH, and TR }\end{array}$ & $\begin{array}{l}\text { (Murphy, Yu } \\
\text { et al. 2003) }\end{array}$ \\
\hline & & & $\begin{array}{l}\text { HCMV strain TB40/E is available as a } \\
\text { BAC clone suitable for genetic } \\
\text { engineering. }\end{array}$ & $\begin{array}{l}\text { (Sinzger, Hahn } \\
\text { et al. 2008) }\end{array}$ \\
\hline & & & $\begin{array}{l}\text { Develops a "gene capture" method to } \\
\text { rescue a large deletion mutant }(15 \mathrm{~kb}) \text { of } \\
\text { HCMV. }\end{array}$ & $\begin{array}{l}\text { (Dulal, Zhang } \\
\text { et al. 2009) }\end{array}$ \\
\hline HHV-6 & $\begin{array}{l}\text { Roseolovirus, } \\
\text { Herpes } \\
\text { lymphotropic } \\
\text { virus }\end{array}$ & $\beta$ & $\begin{array}{l}\text { Develops a single-step production of } \\
\text { viral BACs by introducing the } 160-\mathrm{kb} \\
\text { human herpes virus 6A genome into } \\
\text { BACs by digesting the viral DNA } \\
\text { replicative intermediates with the Sfil } \\
\text { enzyme that cleaves the viral genome in } \\
\text { a single site }\end{array}$ & $\begin{array}{l}\text { (Borenstein } \\
\text { and Frenkel } \\
\text { 2009) }\end{array}$ \\
\hline HHV-7 & Roseolovirus & $\beta$ & & Not available \\
\hline HHV-8 & KSHV & Y & $\begin{array}{l}\text { BAC KSHV can be efficiently shuttled } \\
\text { between bacteria and mammalian cells, } \\
\text { such as BCBL-1, 293, HeLa and E6E7- } \\
\text { immortalized human endothelial cells. }\end{array}$ & $\begin{array}{l}\text { (Delecluse, } \\
\text { Kost et al. } \\
\text { 2001; Zhou, } \\
\text { Zhang } \\
\text { et al. 2002; } \\
\text { Liu 2010) }\end{array}$ \\
\hline
\end{tabular}

Table 1. List of available BACs for human HSV 


\section{2 vGPCR-mediated angiogenesis through activation of p38 and STAT3 in KSHV infected cells using KSHV BACs}

The molecular mechanism whereby viral G protein-coupled receptor (vGPCR) signaling regulates vascular endothelial growth factor (VEGF) expression in Kaposi sarcoma (KS) formation remains somewhat undefined. mECK36 cells, generated by transfection of mice bone marrow endothelial cells with KSHV bacterial artificial chromosome (KSHVBac36), have been reported to be angiogenic, tumorigenic, and suitable for demonstrating a nonredundant role for vGPCR in KSHV-mediated tumorigenesis (Mutlu, Cavallin et al. 2007). In our previous report (Liu 2010), we utilized mECK36, the cells composed of wild-type KSHVBac36 or the cells without vGPCR, namely vGPCR-null KSHVBac36 mutant, to dissect the molecular mechanisms of VEGF secretion induced by vGPCR in the context of KSHV infection. The mice bone marrow endothelial cells (mEC) were obtained from Balb/C An Ncr-nu mice (NCI, Bethesda, MD) bone marrow. Mice femurs were flushed twice with phosphate-buffered saline (PBS), and the elutes were incubated in Dulbecco's modified Eagle's medium (DMEM) media plus 30\% fetal borine serum (FBS) (Gemini Bioproducts, Calabasas, CA), endothelial growth factor (EGF) $0.2 \mathrm{mg} / \mathrm{mL}$ (Sigma, St. Louis, MO), endothelial cell growth factor supplement (ECGS) $0.2 \mathrm{mg} / \mathrm{mL}$ (Sigma), heparin $1.2 \mathrm{mg} / \mathrm{L}$ (Sigma), insulin transferrine selenium (Invitrogen, Carlsbad, CA), penicilin-streptomicin 1\% (Invitrogen), and BME vitamin (VWR Scientific, Rochester, NY). KSHVBac36 was constructed by inserting a full-length recombinant KSHV genome into a bacterial artificial chromosome, KSHVBac36 was transfected into mEC cells to generate mECK36 cells using lipofectamine 2000 (Invitrogen) and selected with hygromycin- $\mathrm{B}$. The cells were then grown in the absence of hygromycin to negatively select cells and therefore generate mECK36-KSHV-Null cells, which lost the KSHV episome (KSHV episome was measured by GFP marker). Next, KSHVBac36 construct was retransfected into mECK36-KSHV-Null cells to generate BBac36. Finally, the genotypic markers of vGPCR were knocked out from KSHVBac36 by transposon mutagenesis to generate ORF74/vGPCR deletion mutant and stably transfected into mECK36-KSHV-Null cells to create BAvGPCR cells in the presence of hygromycin selection. We found (Liu 2010) that vGPCR activates VEGF transcription via p38 MAPK and STAT3 in mECK36 and mECK36-derived cell models. In addition, we also found that in cells containing KSHV genome, STAT3 is tyrosinephosphorylated and translocated into the nucleus, transactivating the target VEGF gene by binding to the specific DNA element TT (N4-5) AA in a vGPCR-dependent manner. Moreover, treatment of mECK36-derived cells with AG490 or a dominant negative STAT3 DNA vector showed strong inhibitory effects on vGPCR-induced VEGF promoter activity. In addition, vGPCR can up-regulate STAT3 mRNA levels. Together, our findings show that vGPCR plays a nonredundant role in STAT3 activation in KSHV infected cells, and this activation plays an important role in the connection of the viral oncogene vGPCR and VEGF up-regulation. Our results indicate that vGPCR has a broad signaling activating capacity in the context of KSHV infection and suggest that the STAT3 pathway could be a good target for preventing KSHV-mediated angiogenesis in KS.

\subsection{Genetic determinants of virus tropism genes using BACs}

Many cell types, including endothelial cells (ECs), myeloid lineage cells, and smooth muscle cells are permissive cells for HCMV persistent replication and latency (Jarvis and Nelson 2007). During acute infection of CMV in immune-compromised patients, a number of cell types, such as ECs, various leukocytes, epithelial cells, hepatocytes, smooth muscle cells, and fibroblasts, 
can be infected because of uncontrolled replication of viruses (Howell, Miller et al. 1979; Myerson, Hackman et al. 1984; Gnann, Ahlmen et al. 1988; Wiley and Nelson 1988; Dankner, McCutchan et al. 1990; Sinzger, Grefte et al. 1995; Read, Zhang et al. 1999; Bissinger, Sinzger et al. 2002). ECs appear to play a critical role in the process of HCMV persistent active infection and maintenance within the host, which is controlled by genetic determinants. Previous studies observed that HCMV strains differed in their ability to infect ECs, which are called EC tropism (MacCormac and Grundy 1999; Sinzger, Schmidt et al. 1999; Kahl, Siegel-Axel et al. 2000). The research on EC tropism has been strengthened by the availability of genetically stable CMV BACs and subsequent mutagenesis of these BACs (Brune, Menard et al. 2001; Scrivano, Sinzger et al. 2011). The switch of cell tropism in different cell types after alternate replication might direct infection from one cell type to the other.

The typical model for tropism is the difference in cell tropism of virus released from EC and fibroblasts. Supernatants from infected human foreskin fibroblasts (HFF) showed a higher ability to infect EC than EC-derived supernatants (Scrivano, Sinzger et al. 2011). Scrivano et al (Scrivano, Sinzger et al. 2011) using mutagenesis of the BAC-cloned HCMV strain TB40/E (TB40-BAC4) found that ECs release a virus progeny of unEC-tropic (not EC-tropic), and retain a progeny of highly EC-tropic; while HFF release both EC-tropic and non EC-tropic virus progeny, HFF progeny is composed of both EC-tropic and non EC-tropic virus populations. The biochemical basis for this phenomenon is due to a different level of $\mathrm{gH} / \mathrm{gL} / \mathrm{pUL}(128,130,131 \mathrm{~A})$ complex in virions (Scrivano, Sinzger et al. 2011). The CMV EC tropism has been characterized by a "genomic tropism island" composed of three open reading frames (ORFs): UL128, UL130, and UL131A. The region of these genes is important for EC tropism (Hahn, Revello et al. 2004; Scrivano, Sinzger et al. 2011). EC-tropic population most likely is a population with a high $\mathrm{gH} / \mathrm{gL} / \mathrm{pUL}(128,130,131 \mathrm{~A})$ content. UL128, UL130, and UL131A are required for replication of HCMV in HUVECs (Hahn, Revello et al. 2004). EC tropism for HCMV is highly dependent on the roles of pUL128, pUL130, and pUL131A (Jarvis and Nelson 2007) in virions. EC-tropism produced by an EC-tropic progeny released by HFF, can be depleted with antibodies directed against pUL131A. They propose that the difference in cell tropism of virus released from EC and fibroblasts is caused by a sorting process. EC strongly and specifically retain EC-tropic viruses through the $\mathrm{gH} / \mathrm{gL} / \mathrm{pUL}(128,130,131 \mathrm{~A})$ complex. Thus, the levels of $\mathrm{gH} / \mathrm{gL} / \mathrm{pUL}(128,130,131 \mathrm{~A})$ complexes could define whether a particle is EC-tropic or not. A disulfide-linked complex between $\mathrm{gH} / \mathrm{gL}$ glycoproteins is required for viral entry and fusion. The gH/gL exists in two distinct forms, one composed of pUL128, pUL130, and pUL131A. The pUL128 and pUL130 proteins are linked with gH/gL; pUL131A is required for infection of ECs. The second distinct form is composed of $\mathrm{gO}$ alone; the gO protein is linked with $\mathrm{gH} / \mathrm{gL}$ and is required for replication in fibroblasts. The $\mathrm{gH} / \mathrm{gL} / \mathrm{pUL128} / \mathrm{pUL130/pUL131A} \mathrm{unit} \mathrm{in}$ virions is mandatory for access into ECs which are $\mathrm{pH}$-dependent. Whereas the $\mathrm{gH} / \mathrm{gL} / \mathrm{gO}$ unit in virions are mandatory for access into fibroblasts which are also $\mathrm{pH}$-independent (Jarvis and Nelson 2007). Recently, results from Wang et al showed (Wang, Yu et al. 2007) that HCMV progenies derived from epithelial cells and fibroblasts are also different. It seems the propensity of cells to release viruses plays a crucial role in the establishment of infection and transfer of viruses to new hosts or the fetus.

In addition to HCMV, EBV also works as a cell type-tropic virus. Hutt-Fletcher et al (HuttFletcher 2007) has established the paradigm that epithelial cells produce a EBV virus 
progeny with high levels of $\mathrm{gH} / \mathrm{gL} / \mathrm{gp} 42$ complexes, facilitating B-cell infection. B-cells in turn, generate virus progeny with low levels of gH/gL/gp42 complexes which efficiently infect epithelial cells, but not B cells. To some extent, this relative switch of cell tropism after alternate replication in epithelial and B-cells directs infection from one cell type to the other.

\subsection{Study of the immune response against the EBV using EBV BACs}

There are three recombinant wild-type EBVs that have been generated so far (Delecluse, Hilsendegen et al. 1998; Kanda, Yajima et al. 2004; Chen, Divisconte et al. 2005). They were generated by the insertion of the prokaryotic F-plasmid (F-factor) in two B95.8 or one Akata strains. Although the insertion sites differ in these three EBV BACs, at the site of the B95.8 deletion (Delecluse, Hilsendegen et al. 1998), or at the major internal repeat region of the B95.5 strain (Chen, Divisconte et al. 2005), or at BXLF1 open reading frame (ORF) in Akata strain (Kanda, Yajima et al. 2004), the insertion site of the F-plasmid does not affect the phenotype of the virus.

\subsubsection{EBV infection}

EBV is tightly related to the development of many human cancers. Chen et al (Chen, Divisconte et al. 2005) has developed a BAC-GFP-EBV (containing 172-kb of the EBV genome) system to monitor early cellular and viral events associated with EBV infection. BAC-GFP-EBV was transfected into the HEK 293T epithelial cell line (Halder, Murakami et al. 2009). Then the progeny virus produced by a chemical was used to immortalize human primary B-cell which can be easily monitored by green fluorescence and proliferation. The results showed a dramatic increase in Ki-67, CD40, and CD23 signals. The viral genes express a pattern of an early burst of lytic gene expression. This up-regulation of lytic gene expression prior to latent genes during early infection strongly suggests that the resulting progeny virus is capable of infecting new primary B-cells (Halder, Murakami et al. 2009). This process may be critical for establishment of latency prior to cellular transformation (Halder, Murakami et al. 2009).

\subsubsection{EBV transformation}

EBV is associated with a number of human malignancies. There is increasing research interest in the molecular functions of these EBV gene products in transformation and evasion from host immune surveillance systems (Izumi 2001). BAC technology made the study on the molecular function of EBV transforming genes feasible because some latent genes such as EBNA1 cannot be maintained in latently infected B cells using traditional cosmid technology (Izumi 2001; Feederle, Bartlett et al. 2010). EBNA1 was found to function as a transactivator of other latent proteins, and was required for replication of the viral genome (Altmann, Pich et al. 2006). When 71kb of EBV DNA genome was amplified in E.coli and transfected into primary B-lymphocyes, Altmann et al (Altmann, Pich et al. 2006) identified that EBV DNA is sufficient to immortalize primary human B lymphocytes. Kempkes et al (Kempkes, Pich et al. 1995; Izumi 2001) also identified EBNA3a as a transforming gene, which contributes primarily to the initiation of cell proliferation (Kempkes, Pich et al. 1995; Izumi 2001). Two genes BALF1 and BHRF1 which encode homologous cellular antiapoptotic viral Bcl-2 proteins (vBcl-2), were suggested to interfere with the cell apoptosis program to counteract cell death, which protects the virus from apoptosis in its host cell during virus synthesis (Altmann and Hammerschmidt 2005). 


\subsubsection{Immune evasion}

Several viral proteins have been found to block immune recognition of viral proteins as antigens during lytic replication, such as BGLF5, BZLF2, BILF1 and BNLF2a (Ressing, van Leeuwen et al. 2005; Rowe, Glaunsinger et al. 2007; Zuo, Thomas et al. 2008; Croft, Shannon-Lowe et al. 2009; Zuo, Currin et al. 2009; Zuo, Quinn et al. 2011). The direct contribution of BNFL2a in immune evasion was evidenced using an EBV BAC which initially disrupted the BNLF2a gene of the B95.8 strain by insertional mutagenesis (Croft, Shannon-Lowe et al. 2009). BNLF2 inhibits transporter associated with antigen (TAP). It encodes a 60 amino acid protein which prevents both peptide- and ATP-binding to TAP complex (Hislop, Ressing et al. 2007). Consequently, when co-expressed with targetantigens, cells expressing BNLF2a show decreased levels of surface human leukocyte antigen (HLA)-class I and are resistant to CD8+ cytotoxic T cell killing (Hislop, Ressing et al. 2007). Croft et al (Croft, Shannon-Lowe et al. 2009) created a targeting plasmid with BNLF2a gene which was replaced by tetracycline resistant cassette. This plasmid was then flanked by FLP recombinase target (FRT) sites. This vector was homologously recombined with the EBV BAC, and designated as $\triangle \mathrm{DBNLF2a}$, which had the tetracycline gene removed by FLP recombinase. $\triangle$ DBNLF2a BACs were then stably transduced into 293 cells, virus replication induced by transfection of a plasmid encoding the EBV lytic switch protein BZLF1 (Feederle, Kost et al. 2000). Compared to wild-type EBV BAC, this recombinant virus induces a strong MHC I T cell response against viral lytic genes than the wild type viruses (Feederle, Bartlett et al. 2010). Overall, these results indicate that BNLF2 prevents the immediate early and early proteins from being efficiently processed and presented to CD8 + T cells during lytic cycle replication. Contrary to BNLF2a in early evasion mechanism in the lytic cycle of EBV, other mechanism seems to operate later during immune evasion (Croft, Shannon-Lowe et al. 2009). Such stage-specific expression of immune evasion genes are a feature of several herpesviruses, such as CMV (Croft, Shannon-Lowe et al. 2009). Taken together, BNLF2a acts in concert with other immuneevasion genes encoded by EBV T-cell surveillance (Croft, Shannon-Lowe et al. 2009).

\section{Non-viral gene functional studies}

\subsection{Translational research by the analysis of entire cancer genomes using BAC arrays}

The development of high-resolution microarray-based comparative genomic hybridization (aCGH) using cDNA of BACs makes it possible for translational research to analyze the entire cancer genome in a single experiment. Well-designed aCGH studies will increase our understanding of the genetic basis of cancer, help to identify novel predictive and prognostic biomarkers for cancer, and molecular therapeutic targets in cancer. Compared to oligonucleotide arrays, BAC arrays have some specific features. BACs have been widely used in aCGH studies (Pinkel and Albertson 2005; Lockwood, Chari et al. 2006; Ylstra, van den Ijssel et al. 2006). The vast majority of array CGH data available today has been generated using BAC CGH arrays. BACs probes vary in length from 150 to $200 \mathrm{~kb}$ (Pinkel and Albertson 2005). The probe of genome-wide BAC arrays range from 2,400 to 32, 000 unique elements in tiling path array, where each BAC overlaps with its contiguous BACs. The resolution (the distance between each DNA target represented on the array) of each BAC array is defined by the number of unique probes it contains (Tan, Lambros et al. 2007). BAC tiling path arrays provide a resolution of up to $50 \mathrm{~kb}$ (Tan, Lambros et al. 2007). The development of a whole-genome BAC tiling path approach has improved resolution of CGH 
by using overlapping clones (Ishkanian, Malloff et al. 2004; Lockwood, Chari et al. 2006). These platforms provide sufficiently strong signals to detect single-copy change, and are able to accurately define the boundaries of genomic aberrations, which can possibly be utilized in archival formalin-fixed, paraffin-embedded (FFPE) tissue (Johnson, Hamoudi et al. 2006; Little, Vuononvirta et al. 2006).

High amounts of high-quality BAC DNA are needed to obtain good array performance (Ylstra, van den Ijssel et al. 2006). BACs DNA yield is generally low when isolated from E. coli (Pinkel and Albertson 2005). Because of the low yields of DNA from isolated BAC clones, DNA amplification is required to generate sufficient quantities of adequately pure BAC DNA for the assay. Therefore a tiling path array is costly and highly labor intensive. In addition, as BAC probes are representative of the human genome, they also contain repetitive sequences, which can result in nonspecific hybridization (Tan, Lambros et al. 2007).

\subsection{Measurement of neuroblastoma DNA copy number aberrations (CNAs)}

BAC technique has increasing been applied in detecting structural changes in chromosomes, such as copy number aberrations (CANs) and rearrangement. Mosse et al (Mosse, Greshock et al. 2005) generated $4135 \mathrm{BAC}$ clones spanning the human genome at about $1.0 \mathrm{Mb}$ resolution as targets for array-based comparative genomic hybridization (aCGH) experiments (Greshock, Naylor et al. 2004). They measured the relevance of neuroblastoma DNA copy number changes (CNAs) in forty-two human neuroblastoma cell lines. They found that all cell lines exhibited CNAs ranging from $2 \%$ to $41 \%$ of the genome. Chromosome 17 showed the highest frequency of CANs. The most frequent region of gain with high-level amplification localized to 2p24.22-2p24.3 detected in $81 \%$ of cell lines (Mosse, Greshock et al. 2005). Potential oncogenes such as MYCN, NAG and DDX1 were located in these regions. The less frequent region of gain localized to 17q23.2, 17q23.3-17q24.1, 17q24.1-17q24.2, 17q25.2-17q25.3 was detected in about $70 \%$ of the cell lines. Potential oncogene BIRC5 was localized in these regions. Although gain of $17 \mathrm{q}$ material was common, this low level gain of chromosomal material was rather complicated (Mosse, Greshock et al. 2005). The most frequent hemizygous deletion localized to a $4.0 \mathrm{Mb}$ region at 1p36.23-36.32, was detected in $60 \%$ of the cell lines. Potential tumor suppressor genes TP73, CHD5, RPL22 and HKR3 were also localized. A 10.4 $\mathrm{Mb}$ region at 11q23.3-11q25 was detected in 36\% of the cell lines, and the potential tumor suppressor gene CHEK1 was found there as well (Mosse, Greshock et al. 2005). Overall, the array $\mathrm{CGH}$ could be reliable in examining DNA copy number aberrations including single copy gain or loss. Compared to the data with standard techniques, data from array CGH correlates well with known aberrations detected by standard techniques. Therefore, array CGH can be applied to identify novel regions of genomic imbalance.

\subsection{Fluorescence in situ hybridization (FISH) analysis of pathological archives with BACs}

It is now known that there are extensive somatic changes, including multiple point mutations (Wood, Parsons et al. 2007; Velculescu 2008), copy number alterations (Weir, Woo et al. 2007; Kubo, Kuroda et al. 2009), and further complex rearrangements (Campbell, Stephens et al. 2008) tumors. But when and where these genetic changes occur during human cancer development remains unclear. Human archival tissue blocks contain 
specimens of human tumors in various stages of development, which are precious in the post-human-genome-sequencing era. Based on their findings and other's work, Sugimura et al (Sugimura, Mori et al. 2010) stated that the intensive application BAC clones as probes for FISH that have exact 'addresses' in the whole genome will become a useful diagnostic tools for pathologists. Thousands of BAC clones are commercially available, and any of them can be used as FISH probes. Sugimura et al tested 100 BAC probes containing different kinase loci in a gastric, colorectal, and lung cancer detection sets (20 cases for each organ) by using tissue microarray (TMA)-FISH technology (Sugimura, Mori et al. 2010). Sugimura et al found that unexpected kinase loci were amplified in a significant proportion of human common solid tumors (Sugimura, Mori et al. 2010). Combinatory chemistry has generated many drugs by targeting kinase genes or their products. Thus, amplification of specific regions on certain kinase genes are amenable to pharmacological intervention which could result in the target specific therapy. Therefore it is reasonable to believe that the FISH-BACs diagnostic system combined with particular kinase probes may provide the practical basis of individual cancer therapy.

\subsection{Interferon-y locus regulation with BACs}

To investigate the regulatory properties of conserved non-coding sequence (CNS) element of interferon- $\gamma$ (Ifng) gene in vivo, Hatton et al (Hatton, Harrington et al. 2006) developed a BAC-based transgenic reporter system to express Ifng gene expression. They introduced a Thy1.1 reporter into exon 1 of Ifng and placed this reporter into a BAC containing approximately $60 \mathrm{~kb}$ upstream of exon 1 of ifng and approximately $100 \mathrm{~kb}$ downstream of exon 4 of ifng sequences. The CNS-22 region of BAC was then flanked with loxP sites (Hatton, Harrington et al. 2006; Wilson and Schoenborn 2006). Because activation of the large BAC transgenic allele unlikely perturbs endogenous alleles (Valjent, Bertran-Gonzalez et al. 2009), potential confounding effects of altered IFNg production were possibly eliminated (Hatton, Harrington et al. 2006). Hatton et al chose Thy1.1 (CD90.1) as a reporter because of its low immunogenicity and easy detection in the context of CD90.2 allotype of the C57BL/ 6 background. The recombined BACs (Ifng-Thy1.1 BAC) containing the Thy1.1 reporter and floxed CNS-22 were microinjected into fertilized C57BL/ 6 oocytes (Hatton, Harrington et al. 2006; Wilson and Schoenborn 2006). As a result, the Ifng-Thy1.1 BAC-in transgene completely mirrored endogenous Ifng gene expression; and conditional deletion of the CNS-22 element from the single copy transgene by Cre recombinase resulted in almost complete loss of Thy1.1 expression in Th1 cells, CD8+ T cells, and NK cells irrespective of activation through the T cell receptor (TCR)-dependent or TCR-independent pathways. Thus, CNS-22 is considered to be critically involved in Ifng gene expression, irrespective of adaptive or innate immune cell lineage (Hatton, Harrington et al. 2006; Wilson and Schoenborn 2006). CNS-22 functions as an enhancer both in vitro and in vivo, which will shed new light on ifng regulation and open up avenues for future investigation.

\subsection{Studies of Kras-mediated pancreatic tumorigenesis with BACs}

Activation of Kras gene by mutation plays a critical role in human pancreatic cancer (Almoguera, Shibata et al. 1988; Shibata, Almoguera et al. 1990). Although the known capability of oncogenic Kras to function as a key initiator of pancreatic malignancy, the mechanism(s) of Kras-caused initiating events are still unclear. This is an important reason 
why prognosis for patients with malignant pancreatic tumors have not entirely improved over the past twenty years (Jemal, Siegel et al. 2006). Moore et al have discovered that the zebrafish develop pancreatic cancer after exposure to chemical mutagens (Moore, Rush et al. 2006). The studies have also shown that mammalian and zebrafish pancreas are significantly similar in anatomy and histology (Wallace and Pack 2003; Chen, Li et al. 2007). Therefore, the Zebrafish has emerged as an experimental model for study of human pancreatic cancer biology (Davison, Woo Park et al. 2008; Park, Davison et al. 2008). Another benefits of working with zebrafish model is their translucency, which greatly improves the visualization of fluorescent trangenes in both embryos and adult zebrafish (Davison, Woo Park et al. 2008). Park et al (Park, Davison et al. 2008) discovered that oncogenic Kras causes pancreatic cell expansion and malignant transformation in the zebrafish exocrine pancreas by utilizing eGFP-Kras BAC transgenes $(160 \mathrm{~kb})$ under the regulation of Ptf1a regulatory elements. Ptf1a induces differentiation, growth and proliferation of pancreatic progenitor cells (Park, Davison et al. 2008). Briefly, they expressed either extended green fluorescent protein (eGFP) alone or eGFP fused to oncogenic Kras in developing zebrafish pancreas and continuously detected the expression of fluorescent transgenes transcutaneously during all stages of development including the adult zebrafish. They first generated polymerase chain reaction (PCR) products encoding the eGFP and eGFP-Kras transgenes flanked by sequences homologous to the $\mathrm{CH} 211-142$ BAC that spans the Pfta1 gene locus. Homologous recombination leads to accurate replacement of the Ptf1a coding sequences with the eGFP and eGFP-Kras transgene (Davison, Woo Park et al. 2008). Their results demonstrate that oncogenic Kras-expressed pancreatic progenitor cells fail to undergo characteristic exocrine differentiation although their initial specification and migration are observed to be normal (Davison, Woo Park et al. 2008; Park, Davison et al. 2008). Blocks of differentiation leads to abnormal accumulation of the undifferentiated progenitor cells, correlates with the formation of invasive pancreatic cancer. Besides similarity in anatomy and histology, Zebrafish pancreatic tumors share several activated signaling pathways with the human pancreatic tumors, including activation of ERK and AKTby phosphorylation, as well as abnormal Hedgehog pathway activation which was justified by the up-regulation of ptc1 mRNA and gli1 mRNA (Park, Davison et al. 2008). These findings provide a unique view of the tumor-initiating effects of oncogenic Kras in a living vertebrate organism, but more important it suggest that BACs transgene targeting other oncogenes or tumor suppressor genes in zebrafish pancreatic cancer may improve our understanding of the human disease.

\subsection{Studies on striatal signaling pathways in central nervous system (CNS) with BACs}

To understand the role of molecular signaling pathways involved in behavioral responses, it is necessary to delineate the molecular events that take place in neurons. This task has been hampered by the complexity of neuronal system. There are hundreds of distinct neuronal populations and these populations are very difficult to distinguish (Valjent, BertranGonzalez et al. 2009). The development of BAC transgenic mice expressing various reporters, epitope tagged-proteins or Cre recombinase driven by specific promoters, greatly facilitates the research in this field. Generally speaking, transgene expression is influenced by copy numbers and site of insertions (positional effects). Large BAC transgenes (BACs contain large fragments $150-200 \mathrm{~kb}$ of mouse genome) have usually a low copy number, are less likely influenced by positional effects, and are able to recapitulate the regulation of endogenous genes much better than shorter transgenes (Yang, Model et al. 1997). Over the past few years, the use of BAC EGFP transgenic mice have generated significant 
development in the analysis of striatal physiology and physiopathology (Valjent, BertranGonzalez et al. 2009). The drd1a-EGFP (EGFP reporter is driven by dopamine D1 receptorD1R promoter), drd2-EGFP (EGFP reporter is driven by dopamine D2 receptor-D2R promoter) and chrm4-EGFP (EGFP reporter is driven by cholinergic receptor, muscarinic 4CHRM4 receptor promoter) BAC transgenic mice have been extensively utilized to investigate the physiological features of striatonigral and striatopallidal medium spiny projection neurons (MSNs) (Lobo, Karsten et al. 2006; Kreitzer and Malenka 2007; Cepeda, Andre et al. 2008; Gertler, Chan et al. 2008). Among these major findings are as follows: 1)D1R-expressing MSNs are less excitable than D2R-MSNs (Lobo, Karsten et al. 2006; Kreitzer and Malenka 2007; Cepeda, Andre et al. 2008; Gertler, Chan et al. 2008) due to different morphology (Gertler, Chan et al. 2008), and some presynaptic factors (Kreitzer and Malenka 2007; Cepeda, Andre et al. 2008). Corticostriatal synapses are activated by repetitive stimulation; in contrast, thalamostriatal synapses are inhibited by repetitive stimulation (Ding, Peterson et al. 2008); 2) D1R-expressing MSNs collaterals are functionally connected primarily with other D1R-MSNs, whereas D2R-expressing neurons collaterals are connected with both D2R- and D1R-MSNs (Taverna, Ilijic et al. 2008). D2R-MSNs synapse with GABAA receptors are stronger (Taverna, Ilijic et al. 2008) and generate greater GABAA receptor-mediated tonic currents (Ade, Janssen et al. 2008) than D1R-MSNs (Janssen, Ade et al. 2009); 3)The single back-propagating action potentials invade more distal dendritic regions in D2R-than in D1R-MSNs, due to a difference in voltage-dependent $\mathrm{Na}+$ channels and Kv4 K+ channels (Day, Wokosin et al. 2008); 4) In the dopamine-depleted striatum, the corticostriatal connections are decreased in D2R neurons (Day, Wang et al. 2006), whereas dendritic excitability is increased in this region (Day, Wokosin et al. 2008; Taverna, Ilijic et al. 2008).

\section{Conclusions and overall perspectives}

Studies on BACs have demonstrated their importance in many research fields, from microbiology, virology, to human genetics, neuroscience, and proteomics (Narayanan 2008; Adamson, Jackson et al. 2011). The power to clone and handle large sized intact genome with high fidelity by BAC has enabled scientists to design and perform both mechanistic and functional studies in an ever expanding field.

\section{Acknowledgements}

This review was supported by the National Institutes of Health grant numbers NIH-FIC (1T90-HG004151-01) for postdoctoral training in Genomics and Hemoglobinopathies, NIH/FIC/NINDS R21 and NIH-RCMI (RR033062).

\section{Glossary}

aCGH: array-based comparative genomic hybridization

BACs: bacterial artificial chromosome

BHV-1: bovine herpesvirus Type 1

CGH: comparative genomic hybridization

CHRM4: cholinergic receptor, muscarinic 4- receptor

CMV: cytomegalovirus

CNAs: copy number changes

CNS: central nervous system 
D1R: dopamine D1 receptor

D2R: dopamine D2 receptor

ECs: endothelial cells

eGFP: extended green fluorescent protein

EHV-1: Equine herpesvirus Type 1

FFPE: archival formalin-fixed, paraffin-embedded

FHV-1: Feline herpesvirus

FISH: fluorescence in situ hybridization

F-plasmid: a fertility plasmid

GPCMV: Guinea pig cytomegalovirus

HCMV or HHV-5: human cytomegalovirus

HFF: human foreskin fibroblasts

HLA: human leukocyte antigen

HSV-1: Herpes simples virus type 1

HSV-2: Herpes simples virus type 2

HUVECs: human umbilical vein endothelial cells

HVS: herpesvirus saimiri

HVT: Turkery herpesvirus

HPV: herpesviruses

Ifng: interferon- $\gamma$

KHV: Koi herpesvirus

KSHV or HHV-8: Kaposi's sarcoma-associated herpesvirus,

LCV: lymphocryptovirus

MDV: Marek's disease virus

mECK36 cells: mouse bone marrow endothelial cells generated by transfection of with KSHVBac36

MSNs: medium spiny projection neurons

VEGF: vascular endothelial growth factor

vGPCR: viral G protein-coupled receptor

VZV or HHV-3: varicella-zoster virus,

KSHVBac36: KSHV bacterial artificial chromosome,

mCMV: murine gammaherpesvirus

MHV-68: Murine cytomegalovirus 68

ORFs: open reading frames

PCR: polymerase chain reaction

PrV: pseudorabies virus

rhCMV: Rhesus cytomegalovirus

RRV: rhesus rhadinovirus

TMA: tissue microarray

\section{References}

Adamson, A. D., D. Jackson, et al. (2011). "Novel approaches to in vitro transgenesis." J Endocrinol 208(3): 193-206.

Ade, K. K., M. J. Janssen, et al. (2008). "Differential tonic GABA conductances in striatal medium spiny neurons." J Neurosci 28(5): 1185-1197. 
Almoguera, C., D. Shibata, et al. (1988). "Most human carcinomas of the exocrine pancreas contain mutant c-K-ras genes." Cell 53(4): 549-554.

Altmann, M. and W. Hammerschmidt (2005). "Epstein-Barr virus provides a new paradigm: a requirement for the immediate inhibition of apoptosis." PLoS Biol 3(12): e404.

Altmann, M., D. Pich, et al. (2006). "Transcriptional activation by EBV nuclear antigen 1 is essential for the expression of EBV's transforming genes." Proc Natl Acad Sci U S A 103(38): 14188-14193.

Bissinger, A. L., C. Sinzger, et al. (2002). "Human cytomegalovirus as a direct pathogen: correlation of multiorgan involvement and cell distribution with clinical and pathological findings in a case of congenital inclusion disease." J Med Virol 67(2): 200-206.

Borenstein, R. and N. Frenkel (2009). "Cloning human herpes virus 6A genome into bacterial artificial chromosomes and study of DNA replication intermediates." Proc Natl Acad Sci U S A 106(45): 19138-19143.

Borst, E. M., G. Hahn, et al. (1999). "Cloning of the human cytomegalovirus (HCMV) genome as an infectious bacterial artificial chromosome in Escherichia coli: a new approach for construction of HCMV mutants." J Virol 73(10): 8320-8329.

Brune, W., C. Menard, et al. (2001). "A ribonucleotide reductase homolog of cytomegalovirus and endothelial cell tropism." Science 291(5502): 303-305.

Campbell, P. J., P. J. Stephens, et al. (2008). "Identification of somatically acquired rearrangements in cancer using genome-wide massively parallel paired-end sequencing." Nat Genet 40(6): 722-729.

Cepeda, C., V. M. Andre, et al. (2008). "Differential electrophysiological properties of dopamine D1 and D2 receptor-containing striatal medium-sized spiny neurons." Eur J Neurosci 27(3): 671-682.

Chen, A., M. Divisconte, et al. (2005). "Epstein-Barr virus with the latent infection nuclear antigen $3 \mathrm{~B}$ completely deleted is still competent for B-cell growth transformation in vitro." J Virol 79(7): 4506-4509.

Chen, S., C. Li, et al. (2007). "Anatomical and histological observation on the pancreas in adult zebrafish." Pancreas 34(1): 120-125.

Copeland, N. G., N. A. Jenkins, et al. (2001). "Recombineering: a powerful new tool for mouse functional genomics." Nat Rev Genet 2(10): 769-779.

Costa, J. L., G. Meijer, et al. (2008). "Array comparative genomic hybridization copy number profiling: a new tool for translational research in solid malignancies." Semin Radiat Oncol 18(2): 98-104.

Cowell, J. K. (2004). "High throughput determination of gains and losses of genetic material using high resolution BAC arrays and comparative genomic hybridization." Comb Chem High Throughput Screen 7(6): 587-596.

Cowell, J. K. and N. J. Nowak (2003). "High-resolution analysis of genetic events in cancer cells using bacterial artificial chromosome arrays and comparative genome hybridization." Adv Cancer Res 90: 91-125.

Croft, N. P., C. Shannon-Lowe, et al. (2009). "Stage-specific inhibition of MHC class I presentation by the Epstein-Barr virus BNLF2a protein during virus lytic cycle." PLoS Pathog 5(6): e1000490.

Dankner, W. M., J. A. McCutchan, et al. (1990). "Localization of human cytomegalovirus in peripheral blood leukocytes by in situ hybridization." J Infect Dis 161(1): 31-36. 
Davison, J. M., S. Woo Park, et al. (2008). "Characterization of Kras-mediated pancreatic tumorigenesis in zebrafish." Methods Enzymol 438: 391-417.

Day, M., Z. Wang, et al. (2006). "Selective elimination of glutamatergic synapses on striatopallidal neurons in Parkinson disease models." Nat Neurosci 9(2): 251-259.

Day, M., D. Wokosin, et al. (2008). "Differential excitability and modulation of striatal medium spiny neuron dendrites." J Neurosci 28(45): 11603-11614.

Delecluse, H. J., T. Hilsendegen, et al. (1998). "Propagation and recovery of intact, infectious Epstein-Barr virus from prokaryotic to human cells." Proc Natl Acad Sci U S A 95(14): 8245-8250.

Delecluse, H. J., M. Kost, et al. (2001). "Spontaneous activation of the lytic cycle in cells infected with a recombinant Kaposi's sarcoma-associated virus." J Virol 75(6): 2921-2928.

Ding, J., J. D. Peterson, et al. (2008). "Corticostriatal and thalamostriatal synapses have distinctive properties." J Neurosci 28(25): 6483-6492.

Dulal, K., Z. Zhang, et al. (2009). "Development of a gene capture method to rescue a large deletion mutant of human cytomegalovirus." J Virol Methods 157(2): 180-187.

Feederle, R., E. J. Bartlett, et al. (2010). "Epstein-Barr virus genetics: talking about the BAC generation." Herpesviridae 1(1): 6.

Feederle, R., M. Kost, et al. (2000). "The Epstein-Barr virus lytic program is controlled by the co-operative functions of two transactivators." Embo J 19(12): 3080-3089.

Gertler, T. S., C. S. Chan, et al. (2008). "Dichotomous anatomical properties of adult striatal medium spiny neurons." J Neurosci 28(43): 10814-10824.

Gnann, J. W., Jr., J. Ahlmen, et al. (1988). "Inflammatory cells in transplanted kidneys are infected by human cytomegalovirus." Am J Pathol 132(2): 239-248.

Greshock, J., T. L. Naylor, et al. (2004). "1-Mb resolution array-based comparative genomic hybridization using a BAC clone set optimized for cancer gene analysis." Genome Res 14(1): 179-187.

Hahn, G., H. Khan, et al. (2002). "The human cytomegalovirus ribonucleotide reductase homolog UL45 is dispensable for growth in endothelial cells, as determined by a BAC-cloned clinical isolate of human cytomegalovirus with preserved wild-type characteristics." J Virol 76(18): 9551-9555.

Hahn, G., M. G. Revello, et al. (2004). "Human cytomegalovirus UL131-128 genes are indispensable for virus growth in endothelial cells and virus transfer to leukocytes." J Virol 78(18): 10023-10033.

Halder, S., M. Murakami, et al. (2009). "Early events associated with infection of EpsteinBarr virus infection of primary B-cells." PLoS One 4(9): e7214.

Hatton, R. D., L. E. Harrington, et al. (2006). "A distal conserved sequence element controls Ifng gene expression by T cells and NK cells." Immunity 25(5): 717-729.

Hislop, A. D., M. E. Ressing, et al. (2007). "A CD8+ T cell immune evasion protein specific to Epstein-Barr virus and its close relatives in Old World primates." J Exp Med 204(8): 1863-1873.

Horsburgh, B. C., M. M. Hubinette, et al. (1999). "Allele replacement: an application that permits rapid manipulation of herpes simplex virus type 1 genomes." Gene Ther 6(5): 922-930.

Howell, C. L., M. J. Miller, et al. (1979). "Comparison of rates of virus isolation from leukocyte populations separated from blood by conventional and FicollPaque/Macrodex methods." J Clin Microbiol 10(4): 533-537.

Hutt-Fletcher, L. M. (2007). "Epstein-Barr virus entry." J Virol 81(15): 7825-7832. 
Imelfort, M., J. Batley, et al. (2009). "Genome sequencing approaches and successes." Methods Mol Biol 513: 345-358.

Ishkanian, A. S., C. A. Malloff, et al. (2004). "A tiling resolution DNA microarray with complete coverage of the human genome." Nat Genet 36(3): 299-303.

Izumi, K. M. (2001). "Identification of EBV transforming genes by recombinant EBV technology." Semin Cancer Biol 11(6): 407-414.

Jackson, R. J. and N. Standart (2007). "How do microRNAs regulate gene expression?" Sci STKE 2007(367): re1.

Janes, D. E., N. Valenzuela, et al. (2011). "Sex chromosome evolution in amniotes: applications for bacterial artificial chromosome libraries." J Biomed Biotechnol 2011(12): 132975.

Janssen, M. J., K. K. Ade, et al. (2009). "Dopamine modulation of GABA tonic conductance in striatal output neurons." J Neurosci 29(16): 5116-5126.

Jarvis, M. A. and J. A. Nelson (2007). "Human cytomegalovirus tropism for endothelial cells: not all endothelial cells are created equal." J Virol 81(5): 2095-2101.

Jemal, A., R. Siegel, et al. (2006). "Cancer statistics, 2006." CA Cancer J Clin 56(2): 106-130.

Johnson, N. A., R. A. Hamoudi, et al. (2006). "Application of array CGH on archival formalin-fixed paraffin-embedded tissues including small numbers of microdissected cells." Lab Invest 86(9): 968-978.

Jones, B. K., B. R. Monks, et al. (1995). "The human growth hormone gene is regulated by a multicomponent locus control region." Mol Cell Biol 15(12): 7010-7021.

Kahl, M., D. Siegel-Axel, et al. (2000). "Efficient lytic infection of human arterial endothelial cells by human cytomegalovirus strains." J Virol 74(16): 7628-7635.

Kanda, T., M. Yajima, et al. (2004). "Production of high-titer Epstein-Barr virus recombinants derived from Akata cells by using a bacterial artificial chromosome system." J Virol 78(13): 7004-7015.

Kempkes, B., D. Pich, et al. (1995). "Immortalization of human B lymphocytes by a plasmid containing 71 kilobase pairs of Epstein-Barr virus DNA." J Virol 69(1): 231-238.

Knipe, D. M., W. Batterson, et al. (1981). "Molecular genetics of herpes simplex virus. VI. Characterization of a temperature-sensitive mutant defective in the expression of all early viral gene products." J Virol 38(2): 539-547.

Kreitzer, A. C. and R. C. Malenka (2007). "Endocannabinoid-mediated rescue of striatal LTD and motor deficits in Parkinson's disease models." Nature 445(7128): 643-647.

Kubo, T., Y. Kuroda, et al. (2009). "Resequencing and copy number analysis of the human tyrosine kinase gene family in poorly differentiated gastric cancer." Carcinogenesis 30(11): 1857-1864.

Lander, E. S., L. M. Linton, et al. (2001). "Initial sequencing and analysis of the human genome." Nature 409(6822): 860-921.

Little, S. E., R. Vuononvirta, et al. (2006). "Array CGH using whole genome amplification of fresh-frozen and formalin-fixed, paraffin-embedded tumor DNA." Genomics 87(2): 298-306.

Liu, M., S. Guo. (2010). "p38 and STAT3 activation by vGPCR in KSHV-infected cells." Virus Adaptation and Treatment(2): 103-113.

Lobo, M. K., S. L. Karsten, et al. (2006). "FACS-array profiling of striatal projection neuron subtypes in juvenile and adult mouse brains." Nat Neurosci 9(3): 443-452. 
Lockwood, W. W., R. Chari, et al. (2006). "Recent advances in array comparative genomic hybridization technologies and their applications in human genetics." Eur J Hum Genet 14(2): 139-148.

Lu, X. H. (2009). "BAC to degeneration bacterial artificial chromosome (BAC)-mediated transgenesis for modeling basal ganglia neurodegenerative disorders." Int Rev Neurobiol 89: 37-56.

MacCormac, L. P. and J. E. Grundy (1999). "Two clinical isolates and the Toledo strain of cytomegalovirus contain endothelial cell tropic variants that are not present in the AD169, Towne, or Davis strains." J Med Virol 57(3): 298-307.

Magin-Lachmann, C., G. Kotzamanis, et al. (2004). "In vitro and in vivo delivery of intact BAC DNA -- comparison of different methods." J Gene Med 6(2): 195-209.

Marchini, A., H. Liu, et al. (2001). "Human cytomegalovirus with IE-2 (UL122) deleted fails to express early lytic genes." J Virol 75(4): 1870-1878.

Meseda, C. A., F. Schmeisser, et al. (2004). "DNA immunization with a herpes simplex virus 2 bacterial artificial chromosome." Virology 318(1): 420-428.

Moore, J. L., L. M. Rush, et al. (2006). "Zebrafish genomic instability mutants and cancer susceptibility." Genetics 174(2): 585-600.

Mosse, Y. P., J. Greshock, et al. (2005). "Measurement and relevance of neuroblastoma DNA copy number changes in the post-genome era." Cancer Lett 228(1-2): 83-90.

Murphy, E., D. Yu, et al. (2003). "Coding potential of laboratory and clinical strains of human cytomegalovirus." Proc Natl Acad Sci U S A 100(25): 14976-14981.

Mutlu, A. D., L. E. Cavallin, et al. (2007). "In vivo-restricted and reversible malignancy induced by human herpesvirus-8 KSHV: a cell and animal model of virally induced Kaposi's sarcoma." Cancer Cell 11(3): 245-258.

Myerson, D., R. C. Hackman, et al. (1984). "Widespread presence of histologically occult cytomegalovirus." Hum Pathol 15(5): 430-439.

Nagaike, K., Y. Mori, et al. (2004). "Cloning of the varicella-zoster virus genome as an infectious bacterial artificial chromosome in Escherichia coli." Vaccine 22(29-30): 4069-4074.

Narayanan, K. (2008). "Intact recombineering of highly repetitive DNA requires reduced induction of recombination enzymes and improved host viability." Anal Biochem 375(2): 394-396.

Park, S. W., J. M. Davison, et al. (2008). "Oncogenic KRAS induces progenitor cell expansion and malignant transformation in zebrafish exocrine pancreas." Gastroenterology 134(7): 2080-2090.

Pinkel, D. and D. G. Albertson (2005). "Array comparative genomic hybridization and its applications in cancer." Nat Genet 37 Suppl(7): S11-17.

Read, R. W., J. A. Zhang, et al. (1999). "Evaluation of the role of human retinal vascular endothelial cells in the pathogenesis of CMV retinitis." Ocul Immunol Inflamm 7(34): 139-146.

Ressing, M. E., D. van Leeuwen, et al. (2005). "Epstein-Barr virus gp42 is posttranslationally modified to produce soluble gp42 that mediates HLA class II immune evasion." J Virol 79(2): 841-852.

Rowe, M., B. Glaunsinger, et al. (2007). "Host shutoff during productive Epstein-Barr virus infection is mediated by BGLF5 and may contribute to immune evasion." Proc Natl Acad Sci U S A 104(9): 3366-3371. 
Saeki, Y., T. Ichikawa, et al. (1998). "Herpes simplex virus type 1 DNA amplified as bacterial artificial chromosome in Escherichia coli: rescue of replication-competent virus progeny and packaging of amplicon vectors." Hum Gene Ther 9(18): 2787-2794.

Schalkwyk, L. C., F. Francis, et al. (1995). "Techniques in mammalian genome mapping." Curr Opin Biotechnol 6(1): 37-43.

Scrivano, L., C. Sinzger, et al. (2011). "HCMV spread and cell tropism are determined by distinct virus populations." PLoS Pathog 7(1): e1001256.

Semprini, S., T. J. Troup, et al. (2007). "Cryptic loxP sites in mammalian genomes: genomewide distribution and relevance for the efficiency of BAC/PAC recombineering techniques." Nucleic Acids Res 35(5): 1402-1410.

Shibata, D., C. Almoguera, et al. (1990). "Detection of c-K-ras mutations in fine needle aspirates from human pancreatic adenocarcinomas." Cancer Res 50(4): 1279-1283.

Shizuya, H., B. Birren, et al. (1992). "Cloning and stable maintenance of 300-kilobase-pair fragments of human DNA in Escherichia coli using an F-factor-based vector." Proc Natl Acad Sci U S A 89(18): 8794-8797.

Sinzger, C., A. Grefte, et al. (1995). "Fibroblasts, epithelial cells, endothelial cells and smooth muscle cells are major targets of human cytomegalovirus infection in lung and gastrointestinal tissues." J Gen Virol 76 ( Pt 4)(Pt 4): 741-750.

Sinzger, C., G. Hahn, et al. (2008). "Cloning and sequencing of a highly productive, endotheliotropic virus strain derived from human cytomegalovirus TB40/E." J Gen Virol 89(Pt 2): 359-368.

Sinzger, C., K. Schmidt, et al. (1999). "Modification of human cytomegalovirus tropism through propagation in vitro is associated with changes in the viral genome." J Gen Virol 80 ( Pt 11)(Pt 11): 2867-2877.

Sparwasser, T. and G. Eberl (2007). "BAC to immunology--bacterial artificial chromosomemediated transgenesis for targeting of immune cells." Immunology 121(3): 308-313.

Stavropoulos, T. A. and C. A. Strathdee (1998). "An enhanced packaging system for helperdependent herpes simplex virus vectors." J Virol 72(9): 7137-7143.

Sugimura, H., H. Mori, et al. (2010). "Fluorescence in situ hybridization analysis with a tissue microarray: 'FISH and chips' analysis of pathology archives." Pathol Int 60(8): 543-550.

Tan, D. S., M. B. Lambros, et al. (2007). "Getting it right: designing microarray (and not 'microawry') comparative genomic hybridization studies for cancer research." Lab Invest 87(8): 737-754.

Taverna, S., E. Ilijic, et al. (2008). "Recurrent collateral connections of striatal medium spiny neurons are disrupted in models of Parkinson's disease." J Neurosci 28(21): 5504-5512.

Townes, T. M., J. B. Lingrel, et al. (1985). "Erythroid-specific expression of human betaglobin genes in transgenic mice." Embo J 4(7): 1715-1723.

Tunster, S. J., M. Van De Pette, et al. (2011). "BACs as tools for the study of genomic imprinting." J Biomed Biotechnol 2011(13): 283013.

Valjent, E., J. Bertran-Gonzalez, et al. (2009). "Looking BAC at striatal signaling: cell-specific analysis in new transgenic mice." Trends Neurosci 32(10): 538-547.

Velculescu, V. E. (2008). "Defining the blueprint of the cancer genome." Carcinogenesis 29(6): 1087-1091.

Venter, J. C., M. D. Adams, et al. (2001). "The sequence of the human genome." Science 291(5507): 1304-1351. 
Wallace, K. N. and M. Pack (2003). "Unique and conserved aspects of gut development in zebrafish." Dev Biol 255(1): 12-29.

Wang, D., Q. C. Yu, et al. (2007). "Human cytomegalovirus uses two distinct pathways to enter retinal pigmented epithelial cells." Proc Natl Acad Sci U S A 104(50): 20037-20042.

Warden, C., Q. Tang, et al. (2011). "Herpesvirus BACs: past, present, and future." J Biomed Biotechnol 2011(27): 124595.

Weir, B. A., M. S. Woo, et al. (2007). "Characterizing the cancer genome in lung adenocarcinoma." Nature 450(7171): 893-898.

Wiley, C. A. and J. A. Nelson (1988). "Role of human immunodeficiency virus and cytomegalovirus in AIDS encephalitis." Am J Pathol 133(1): 73-81.

Wilson, C. B. and J. Schoenborn (2006). "BACing up the interferon-gamma locus." Immunity 25(5): 691-693.

Wood, L. D., D. W. Parsons, et al. (2007). "The genomic landscapes of human breast and colorectal cancers." Science 318(5853): 1108-1113.

Wussow, F., H. Fickenscher, et al. (2009). "Red-mediated transposition and final release of the mini-F vector of a cloned infectious herpesvirus genome." PLoS One 4(12): e8178.

Yang, X. W., P. Model, et al. (1997). "Homologous recombination based modification in Escherichia coli and germline transmission in transgenic mice of a bacterial artificial chromosome." Nat Biotechnol 15(9): 859-865.

Ylstra, B., P. van den Ijssel, et al. (2006). "BAC to the future! or oligonucleotides: a perspective for micro array comparative genomic hybridization (array CGH)." Nucleic Acids Res 34(2): 445-450.

Zhang, Z., J. Rowe, et al. (2007). "Genetic analysis of varicella-zoster virus ORF0 to ORF4 by use of a novel luciferase bacterial artificial chromosome system." J Virol 81(17): 9024-9033.

Zhou, F. C., Y. J. Zhang, et al. (2002). "Efficient infection by a recombinant Kaposi's sarcomaassociated herpesvirus cloned in a bacterial artificial chromosome: application for genetic analysis." J Virol 76(12): 6185-6196.

Zhou, G. and B. Roizman (2005). "Characterization of a recombinant herpes simplex virus 1 designed to enter cells via the IL13Ralpha2 receptor of malignant glioma cells." J Virol 79(9): 5272-5277.

Zuo, J., A. Currin, et al. (2009). "The Epstein-Barr virus G-protein-coupled receptor contributes to immune evasion by targeting MHC class I molecules for degradation." PLoS Pathog 5(1): e1000255.

Zuo, J., L. L. Quinn, et al. (2011). "The Epstein-Barr virus-encoded BILF1 protein modulates immune recognition of endogenously processed antigen by targeting major histocompatibility complex class I molecules trafficking on both the exocytic and endocytic pathways." J Virol 85(4): 1604-1614.

Zuo, J., W. Thomas, et al. (2008). "The DNase of gammaherpesviruses impairs recognition by virus-specific CD8+ T cells through an additional host shutoff function." J Virol 82(5): 2385-2393. 


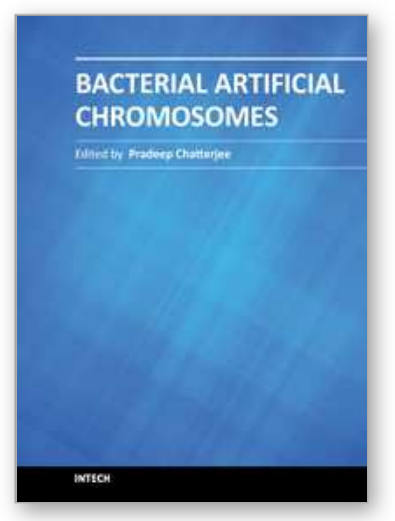

\author{
Bacterial Artificial Chromosomes \\ Edited by Dr Pradeep Chatterjee
}

ISBN 978-953-307-725-3

Hard cover, 148 pages

Publisher InTech

Published online 25, November, 2011

Published in print edition November, 2011

This book focuses on the numerous applications of Bacterial Artificial Chromosomes (BACs) in a variety of studies. The topics reviewed range from using BAC libraries as resources for marsupial and monotreme gene mapping and comparative genomic studies, to using BACs as vehicles for maintaining the large infectious DNA genomes of viruses. The large size of the insert DNA in BACs and the ease of engineering mutations in that DNA within the bacterial host, allowed manipulating the BAC-viral DNA of Varicella-Zoster Virus. Other reviews include the maintenance and suitable expression of foreign genes from a Baculovirus genome, including protein complexes, from the BAC-viral DNA and generating vaccines from BAC-viral DNA genomes of Marek's disease virus. Production of multi-purpose BAC clones in the novel Bacillus subtilis host is described, along with chapters that illustrate the use of BAC transgenic animals to address important issues of gene regulation in vertebrates, such as functionally identifying novel cis-acting distal gene regulatory sequences.

\title{
How to reference
}

In order to correctly reference this scholarly work, feel free to copy and paste the following:

Mingli Liu, Shanchun Guo, Monica Battle and Jonathan K. Stiles (2011). Gene Functional Studies Using Bacterial Artificial Chromosome (BACs), Bacterial Artificial Chromosomes, Dr Pradeep Chatterjee (Ed.), ISBN: 978-953-307-725-3, InTech, Available from: http://www.intechopen.com/books/bacterial-artificialchromosomes/gene-functional-studies-using-bacterial-artificial-chromosome-bacs-

\section{INTECH}

open science | open minds

\section{InTech Europe}

University Campus STeP Ri

Slavka Krautzeka 83/A

51000 Rijeka, Croatia

Phone: +385 (51) 770447

Fax: +385 (51) 686166

www.intechopen.com

\section{InTech China}

Unit 405, Office Block, Hotel Equatorial Shanghai

No.65, Yan An Road (West), Shanghai, 200040, China

中国上海市延安西路65号上海国际贵都大饭店办公楼 405 单元

Phone: +86-21-62489820

Fax: $+86-21-62489821$ 
(C) 2011 The Author(s). Licensee IntechOpen. This is an open access article distributed under the terms of the Creative Commons Attribution 3.0 License, which permits unrestricted use, distribution, and reproduction in any medium, provided the original work is properly cited. 